\title{
Depression and Quality of Life in Patients With Type 2 Diabetes
}

\author{
Firooze Derakhshanpour ${ }^{1}$; Mohammad Ali Vakili ${ }^{2, *}$; Maryam Farsinia ${ }^{3}$; Kamal Mirkarimi ${ }^{4}$ \\ ${ }_{1}^{1}$ Golestan Psychiatric Research Center, Golestan University of Medical Sciences, Gorgan, IR Iran \\ 2 Department of Health and Social Medicine, Health Management and Social Development Research Center, Golestan University of Medical Sciences, Gorgan, IR Iran \\ ${ }^{3}$ Gepartment of Health and Social Medicine, Health Mana \\ ${ }^{3}$ Golestan University of Medical Sciences, Gorgan, IR Iran
${ }^{H}$ Health Management and Social Development Research Center, Golestan University of Medical Sciences, Gorgan, IR Iran \\ ${ }^{*}$ Corresponding Author: Mohammad Ali Vakili, Department of Health and Social Medicine, Health Management and Social Development Research Center, Golestan University of \\ Medical Sciences, Gorgan, IR Iran. Tel: +98-1732421221, Fax:+98-1732421657, E-mail:vakili@goums.ac.ir
}

Received: February 5, 2015; Revised: March 4, 2015; Accepted: March 24, 2015

\begin{abstract}
Background: Frequency of mood disorders in patients with chronic diseases, especially diabetes and its effects on life quality are dramatically increasing.

Objectives: This study aimed to investigate the relation between depression and quality of life in patients with diabetes.

Patients and Methods: This is a cross sectional survey. Subjects were selected from 330 eligible people referred to the only diabetes clinic in Gorgan City during 6 months, using systematic random sampling. Beak Depression questionnaire and the brief questioner with 26 questions recommended by the World Health Organization (WHOQOL-BREF) were used to measure depression and quality of life, respectively. Data were analyzed through descriptive methods, Chi-square, Independent t test and linear regression model using SPSS16; moreover, $\mathrm{P}$ value $<0.05$ was considered as significant.

Results: In total, 330 patients with diabetes (35.5\% male and 64.5\% women) were studied. The mean and standard deviation of their age and years involved with diabetes were $50.6 \pm 9.0$ and $5.4 \pm 4.5$ years, respectively. Range of age was $25-75$ years, as well. The prevalence of depression in all patients with diabetes was $58.2 \%$ (124 mild, 56 medium, and 12 with severe depression). Hypertension was $13.9 \%$ more in diabetic patients with depression (Pvalue $<0.001$ ) and physical activity in $24.7 \%$ of the cases was less with a meaningful difference (P value $=0.01$ ). The mean and standard deviation of quality of life in diabetic patients with and without depression was $50.7 \pm 14$ and $60.5 \pm 13.3$, respectively that was significant in two groups $(\mathrm{P}<0.0001)$.

Conclusions: The prevalence of depression is high in patients with diabetes and has a considerable impact on the consequences of diabetes and quality of life too.
\end{abstract}

Keywords: Type 2 Diabetes Mellitus; Quality of Life; Depression

\section{Background}

Diabetes is the most common metabolic disease, with an increasing prevalence that reduces life expectancy to a third $(1,2)$. There are 200 million people with diabetes worldwide (about 5\% of adult population) (3). According to a nationwide study in 2001 , the prevalence of diabetes in Iran was estimated at $4.67 \%$ among the population older than 20 years (4). Diabetes is usually associated with short-term complications such as hypoglycemia, and long-term complications like cardiovascular diseases, neuropathy, nephropathy, and retinopathy. Amid, psychiatric problems have been less studied or treated compared to other complications. Patients with diabetes are twice exposed to the risk of psychiatric diseases compared to normal population, and according to some studies, one in every 5 patients with diabetes suffer from depression $(5,6)$.

Diabetes doubles the likelihood of depression. In a study by Asghar et al. symptoms of depression were observed in $29 \%$ of men and $30.5 \%$ of women with diabetes in Bangladesh villages (7). In Khamseh et al. study, 71.8\% of patients with diabetes had major depression (8), and in Sepehrmanesh study in Kashan, this rate was $57.7 \%$ among women and $41 \%$ among men (9).

Many factors can be affected by treatment of the disease, including physical function and daily activity, social relationships, quality of life, and personal mood. As the disease affects patient's self-confidence and increase his or her fear of worsening complications, the risk of psychiatric diseases increases (10).

Depression is associated with increased risk of high blood glucose, complications of diabetes, cardiovascular diseases, and possibly patient's reduced compliance too (11-14). Furthermore, diabetic patients with depression have greater burden of treatment costs and referrals than those patients without depression (15).

Various studies have shown that unlike normal people, patients with diabetes have lower quality of life, and this is much more pronounced in those suffering from complications of diabetes; depression also has a significant effect on patients' quality of life (16-18). In a study in

Copyright (C) 2015, Iranian Red Crescent Medical Journal. This is an open-access article distributed under the terms of the Creative Commons Attribution-NonCommercial 4.0 International License (http://creativecommons.org/licenses/by-nc/4.0/) which permits copy and redistribute the material just in noncommercial usages, provided the original work is properly cited. 
Yazd, the mean score of quality of life in studied patients was 25.65 out of 60 , and in patients with complications like retinopathy or neuropathy, this score was lower compared to patients without these complications (19).

Comorbidity of depression and diabetes can have a cumulative effect on people's functions (20). Diagnosis of depression in these patients is particularly important in order to reduce complications and improve quality of life. Li et al. reported that depression was not diagnosed in $45 \%$ of diabetic patients (21). Depression leads to patient's noncompliance, blood glucose mismanagement, and other physical complications (11, 19, 22). Ciechanowski et al. reported that depressed patients are unable to comply with dietary regimen or manage blood glucose, and in this respect, they are clearly different from non-depressed patients (23). With regard to the effect of diabetes with depression on the quality of life, in 2004, Filakovic et al. demonstrated that comorbidity of depression with diabetes further lowers patients' quality of life by many folds (24).

\section{Objectives}

Although several studies have been conducted on either quality of life or depression in diabetic patients, there are few studies on the relationship between quality of life and depression in diabetic patients. Moreover, given that failure to diagnose depression in diabetic patients is commonplace, the need to identify and screen psychiatric disorders in patients with chronic diseases, especially diabetes, and the impact of depression on the quality of life, this article aimed to investigate the relationship between depression and quality of life in patients with diabetes using medical records at diabetics' clinic in Gorgan.

\section{Patients and Methods}

\subsection{Study Design}

A cross-sectional study was implemented. The current survey was approved in the 46 Ethics Committee of Golestan University of Medical Sciences (No. 327123847).

\subsection{Participants}

In total, 330 eligible patients with diabetes were selected from patients admitted to the only specialized diabetic clinic in city of Gorgan, North of Iran, at 5th Azar Hospital, in the first 6 months of 2012. Inclusion criteria were confirmed diabetic record by the clinic specialist, age range of 25 - 75 years, having regular visits to the clinic, being under treatment with insulin and oral medication, not having type I diabetes, and not being treated for psychological health problems. All patients were invited to participate by a trained expert at the clinic. Patients were assured of the confidentiality of data and their informed consents were obtained. According to Ethics Committee guidelines, patient information remains confidential to the researcher.

\subsection{Sample Size}

Based on the Eren et al. study (25), the correlation between the depression and quality of life $(r=0.39), 95 \%$ confidence interval, and $90 \%$ power test, 66 diabetic patients with depression were needed. To achieve that and with respect to $20 \%$ estimation of depression in patients with diabetes $(5,7), 330$ patients with type 2 diabetes were investigated (Equation 1).

1)

$$
\begin{aligned}
& C=\frac{1}{2} \operatorname{Ln}\left|\frac{1+r}{1-r}\right|, r=0.39, \mathrm{Z}_{1-\frac{\alpha}{2}}=1.96, \mathrm{Z}_{1-\beta}=1.28, n_{0} \\
& =\left[\left(\frac{\mathrm{Z}_{1-\frac{\alpha}{2}}+\mathrm{Z}_{1-\beta}}{C}\right)^{2}\right]+3=66, n=\frac{n_{0}}{p_{0}}=\frac{66}{0.2}=330
\end{aligned}
$$

\subsection{Sample Frame}

Diabetes clinic is the only specialized and state referral clinic in Gorgan that is supported by 5th Azar Hospital and is also one of the 3 state hospitals belonged to the Golestan University of Medical Sciences. Since more than $80 \%$ of attended patients with diabetes to the health centers, had been visited by the aforementioned clinic (with continuous access) and according to the all patients with record ( $\mathrm{N}=1150), 330$ subjects were finally selected using systematic sampling with an interval of $3(K=N / n=3)$, in the way that the first patient was randomly selected. Then, a number was selected from 1 to 3 (the second patient was selected). In other cases and with respect to the sampling interval as 3, other samples were included (such as number 5, 8 to 989). The next patient would be elected if the selected sample was not eligible. All patients were studied from March to August 2012.

\subsection{Instrument}

Demographic questionnaire was completed in the presence of patients, and related data to the disease and its complications were obtained from their records. Beck Depression Inventory (BDI) was used to assess depression, and the short version (26 items) of the World Health Organization Quality of Life Questionnaire (WHOQOLBREF) was used to assess quality of life. BDI contains 21 items, which evaluates signs of depression, including sadness, guilt, loss of interest, social isolation, and suicidal ideation. Each item has rated on a 4-point Likert scoring style from 0 for the lowest to 3 for the highest. Each option is determined from mild to severe (0 for psychological health, and scores 1, 2, and 3 for mild, moderate, and severe disorders, respectively). Overall depression score for each patient is found by summing up scores of all items, ranging from 0 to 63, and higher scores indicate more severe depression, as follows: 0 to 15 means no depression, 16 to 31 mild depression, 32 to 47 moderate depression, and 48 to 63 severe depression. 
Persian version of Beck Anxiety Inventory was tested and approved by Kaviani and Mousavi. Its reliability was determined through internal consistency using Cronbach $\alpha$ of $84 \%$, and correlation was obtained $70 \%$ using split half method (26). In this study, Cronbach $\alpha$ for the reliability of questionnaire for diabetic patients was found 0.77 , which indicates the questionnaire was suitable for this study. Diez-Quevedo et al. also studied it in Diagnosing Mental Disorders in 1003 General Hospital Spanish Inpatients in 2001 (27).

In the 26-item WHOQOL-BREF, the first two items assess general health status and quality of life, and the next 24 items assess quality of life in 4 domains of physical health, psychological health, social relationships, and environment using 3, 6, 7 and 8 items, respectively. In this study, each item scored from 1 to 5 . The 5-point Likert scale was applied for items 1 and 15 (very bad, bad, not bad, good, and very good), items 2, and 16 to 25 (very unhappy, unhappy, not unhappy, happy, and very happy), items 3 to 14 (not at all, a little, medium, high, and very high), and for item 26 (never, rarely, occasionally, often, and always). Scoring for items 3, 4, and 26 was in reverse. To compare domains and the first two items in depressed and nondepressed groups of patients, quality of life score for each patient $\left(X_{i}\right)$ was converted into scores between 0 and 100 using the following Equation 2 (28-31):

$$
Y_{i}=\frac{X_{i}-\min \mathrm{XXX}}{\max \left(X_{i}\right)-\mathrm{XXX}}
$$

Validity and reliability of WHOQOL-BREF have been reported favorable in many native and foreign studies $(17,30,32)$. In the present study, validity of this questionnaire was estimated according to internal consistency for the whole scale of $85 \%$, physical health $78 \%$, psychological health $80 \%$, social relationships $69 \%$, and environment $84 \%$.

\subsection{Data Analysis}

The normality of QOL scores and its dimensions were tested and confirmed by Kolmogorov-Smirnov test. We followed the QOL scoring guideline to score missing data in the questionnaire. Where an item was missing, we substituted the mean of other items in the domain. Also, when more than 2 items were missing from a domain, we did not calculate the domain score. The missing data in BDI Questionnaire were replaced using median near points. To describe data, central and dispersion indicators such as mean and standard deviation were calculated. To compare qualitative characteristics of depressed and non-depressed patients, Chi-square test was used. Mean scores of QOL and its sub-domains, age, and duration of disease in two groups were analyzed using Independent $t$ test. We conducted multiple linear regression analyses to assess prediction of QOL scores and its relationship with other variables.
In addition, we used scatter diagrams to visualize the relationship between dependent variable and each metric independent variable to be sure that they are linear. In addition, we also checked whether the relationship between dependent variable and categorical independent variables is homoscedastic. We also checked the normality of the distribution of errors. Data were analyzed using SPSS-16 software. The significance level was regarded as 0.05 .

\section{Results}

A total of 330 diabetic patients (35.5\% men, and 64.5\% women) were studied, with mean and standard deviation of age and history of disease of $50.6 \pm 9$ and $5.4 \pm$ 4.5 years, respectively, and age range of 25 to 75 years. The prevalence of depression in all diabetic patients was $58.2 \%$, of whom 124 patients (64.6\%) had mild depression, 56 (29.2\%) moderate depression, and 12 (6.2\%) severe depression. This was in $64.8 \%$ of men and $61.5 \%$ of women, with insignificant differences between them. Depression was observed in $45.1 \%$ of the single diabetic patients and in $60.6 \%$ of married ones, with significant difference $(P=0.039)$. More than $50 \%$ of depressed diabetic patients and $62.5 \%$ of non-depressed diabetic patients were literate, and the difference between two groups was significant. However, there were insignificant differences between the two groups in terms of employment status (Table 1).

Table 1. Demographic Characteristics of Patients With Type 2 Diabetes Admitted to 5th Azar Diabetes Clinic ${ }^{a}$

\begin{tabular}{|c|c|c|c|}
\hline Variable & $\begin{array}{l}\text { Non-Depressed } \\
\qquad(\mathbf{n}=\mathbf{1 3 8})\end{array}$ & $\begin{array}{c}\text { Depressed } \\
(\mathbf{n}=192)\end{array}$ & P Value \\
\hline Age, y & $49.9 \pm 8.8$ & $51.0 \pm 9.1$ & N.S \\
\hline $\begin{array}{l}\text { Duration of } \\
\text { illness }\end{array}$ & $5.00 \pm 4.6$ & $5.6 \pm 4.3$ & N.S \\
\hline Gender & & & N.S \\
\hline Male & $43(31.2)$ & $95(68.8)$ & \\
\hline Female & $74(38.5)$ & $118(61.5)$ & \\
\hline Marital status & & & 0.039 \\
\hline Single & $28(54.9)$ & $23(45.1)$ & \\
\hline Married & $110(39.4)$ & $169(60.6)$ & \\
\hline Education & & & 0.008 \\
\hline Literate & $90(48.1)$ & $97(51.9)$ & \\
\hline Illiterate & $48(33.6)$ & $95(66.4)$ & \\
\hline Occupation & & & N.S \\
\hline Employed & $56(42.8)$ & $75(57.3)$ & \\
\hline Unemployed & $82(41.2)$ & $117(58.8)$ & \\
\hline
\end{tabular}


DerakhshanpourF et al.

Mean and standard deviation of depression score according to BDI was $29.4 \pm 10.1$ in depressed patients, and $8.1 \pm 4.1$ in non-depressed patients, with a significant difference between them $(\mathrm{P}<0.001)$.

Comparison of the relationship between clinical characteristics and depression in patients with diabetes showed insignificant differences between the two groups with respect to dietary regimen, diabetes complications (retinopathy, neuropathy, and nephropathy), and duration of the disease. However, hypertension was $13.9 \%$ more $(\mathrm{P}<$ 0.001 ), and physical activity $24.7 \%$ less in diabetic patients with depression, and the difference between groups was significant $(\mathrm{P}=0.01)$ (Table 2 ).

Comparing scores of various domains of quality of life between depressed and non-depressed patients with diabetes using Independent t test indicated significant lower mean scores in subscales of general health, quality of life in general, psychological health, environment, and overall score of quality of life in depressed diabetic patients at error level of 0.001 . However, in physical health domain, mean score was lower in depressed patients, with a significant difference $(\mathrm{P}=0.009)$ (Table 3 ).

Linear regression model of prediction of quality of life score with independent variables of age, gender, duration of disease, hypertension, diabetes complications, education, marital status, occupation, physical activity, and depression score showed significant and inverse relationship between overall score of quality of life and variables of physical activity, diabetes complications or otherwise, and depression score $(\mathrm{P}=0.01)$ (Table 4).
Table 2. Clinical Details of Depressed and Non-depressed Patients With Diabetes ${ }^{\text {a }}$

\begin{tabular}{lccc}
\hline Variable & $\begin{array}{c}\text { Non-depressed } \\
(\mathbf{n}=\mathbf{1 3 8})\end{array}$ & $\begin{array}{c}\text { Depressed } \\
(\mathbf{n}=\mathbf{1 9 2})\end{array}$ & P Value \\
\hline Diet compliance & & & 0.09 \\
Yes & $118(85.5)$ & $150(78.1)$ & \\
\hline No & $20(14.5)$ & $42(21.9)$ & \\
Hypertension & & & 0.01 \\
\hline Yes & $38(27.5)$ & $79(41.4)$ & \\
\hline No & $100(72.5)$ & $112(58.6)$ & \\
\hline $\begin{array}{l}\text { Diabetes compli- } \\
\text { cations }\end{array}$ & & & \\
\hline No & $25(18.1)$ & $28(14.6)$ & \\
\hline Yes & $113(81.9)$ & $164(85.4)$ & \\
\hline Retinopathy & $7(5.1)$ & $17(8.9)$ & \\
\hline Neuropathy & $56(40.6)$ & $70(36.5)$ & \\
\hline Nephropathy & $21(15.2)$ & $23(12.0)$ & \\
\hline $\begin{array}{l}\text { More than one } \\
\text { Complication }\end{array}$ & $29(21.0)$ & $54(28.1)$ & \\
\hline Physical activity & & & \\
\hline Yes & $83(60.6)$ & $69(35.9)$ & \\
\hline No & $54(39.4)$ & $123(64.1)$ & \\
\hline
\end{tabular}

a Data are presented as No.(\%).

Table 3. Sores in Different Areas of Quality of Life in Depressed and Non-Depressed Patients With Diabetes a

\begin{tabular}{lccc}
\hline Domain & Non-depressed & Depressed & PValue \\
\hline General health $($ item 1) & $90.8 \pm 12.1$ & $38.9 \pm 26.2$ & $<0.001$ \\
Overall quality of life $($ item 2) & $74.8 \pm 15.8$ & $45.4 \pm 14.8$ & $<0.001$ \\
Physical health & $64.8 \pm 21.3$ & $58.3 \pm 22.8$ & 0.009 \\
Psychological health & $46.0 \pm 22.5$ & $36.8 \pm 21.1$ & $<0.001$ \\
Environment & $52.7 \pm 19.1$ & $43.4 \pm 21.5$ & $<0.001$ \\
Social relationships & $90.2 \pm 15.9$ & $90.5 \pm 14.4$ & N.S \\
Overall score of quality of life & $60.5 \pm 13.3$ & $50.7 \pm 14.0$ & $<0.001$ \\
\hline
\end{tabular}

${ }^{\mathrm{a}}$ Data are presented as Mean \pm SD.

\begin{tabular}{lcccccc}
\hline Table 4. Regression Analysis of Overall Quality of Life Score and Associated Variables & & \\
\cline { 1 - 4 } Variable & \multicolumn{2}{c}{ Non-Standard } & Standard & \multirow{2}{*}{ t test } & \multirow{2}{*}{ P Value } \\
\cline { 2 - 4 } & $\mathbf{B}$ & Standard Error & Beta & & \\
\hline Constant & 73.92 & 2.82 & - & 26.26 & $<0.001$ \\
Depression score & -0.43 & 0.06 & -0.39 & -7.80 & $<0.001$ \\
Physical activity & -3.87 & 1.48 & -0.13 & -2.63 & 0.009 \\
Diabetes complication & -5.20 & 1.94 & -0.13 & -2.68 & 0.008 \\
\hline
\end{tabular}




\section{Discussion}

The present study results are in line with the results in other studies, and suggest high prevalence of depression among patients with diabetes $(7-9,19)$. According to the present study, $58.2 \%$ of participants had moderate to severe depression and $15.5 \%$ had mild depression, i.e., $73.7 \%$ of the patients are likely to have depression. In a study by Nedjat et al. (28), $28 \%$ of patients were depressed and $38 \%$ had mild depression, making a total of $66 \%$. The rate of depression was $41.9 \%$ in Larijani, and 53.3\% in Sepehrmanesh studies $(9,19,21)$. Evidence suggests a 2-way relationship between depression and type 2 diabetes. Kahn et al. argue that not only depression could result from diabetes; but also it is a risk factor for the onset of diabetes (22). Depression is associated with $60 \%$ increased risk of type 2 diabetes, while diabetes only causes an increased risk of depression by about 15\% (23).

Depression is usually more prevalent among women than men. However, in the present study, there was an insignificant difference between sexes in the prevalence of depression, which is in line with results of Pinquart et al. (33).

In the present study, the mean overall quality of life score in depressed patients was $50.68 \pm 14.04$, which was significantly lower than non-depressed patients with $60.46 \pm 13.27$, and is close to the results found by Nedjat et al. (28). In psychiatric and habitat areas and overall score, the differences between groups was significant, and among depressed patients, mean score was lower, which is in line with other studies $(6,25,28)$. Only in social relationships domain, the difference between the two groups was insignificant. Perhaps, it could be attributed to rich relationships between patients and their family and relatives, which often become richer at times of disease.

Depression can affect physical outcomes such as myocardial infarction, life expectancy in cancer patients, and infections. Also, it explains the effect of depression on immune system the most. Other reasons for this effect can be due to the fact that depression in diabetic patients affects compliance, proper dietary regimen, smoking, and exercise (7). In a study by Lin et al., it was confirmed that depressed patients perform more poorly than other patients in compliance with personal care, including proper nutrition, exercise, compliance with treatment and prevention (34). In another study it was found that regarding incident disability and mortality, the effects of interaction between diabetes and depression seemed to be synergistic (that is, greater than the additive main effects of diabetes and depression).

Unutzer et al. compared depressed patients and 8 groups of patients with chronic diseases, and found that depressed patients showed greater reduction in the quality of life than the other 8 groups, and this effect remained, even after eliminating factors such as age, gender, and chronic diseases (35). In the present study, regression analysis revealed that depression had the most influence on quality of life.
High prevalence of comorbidity of depression with diabetes in patients indicates that effect of depression comorbidity on the quality of life can significantly affect outcomes of the disease, and early diagnosis of depression can improve quality of life (25).

Study limitations included lack of measurement of HbA1C, which could help assess better the patients' blood glucose, and its effect on disease complications. It is, therefore, suggested that its measurement be taken into consideration in future similar studies.

Given the results of this and other studies, it seems that there is high prevalence of depression among patients with diabetes, and it has a significant effect on diabetes outcomes and quality of life. It is recommended that besides regular doctors' visits in terms of physical problems, the psychiatric problems and quality of life of these patients should also be more considered. Regular psychiatrist visits, or psychological assessments for screening mental disorders can help early diagnosis of these disorders.

Our survey weaknesses were as follow:1) we used self-administered questionnaire, which could include patients' bias, 2) participants may not have fully understood or have misinterpreted questions that might have biased the responses, and 3) we conducted a cross-sectional method that provided us with information for that particular issue in time. However, our study strong points can be mentioned as covering more than $80 \%$ of patients with diabetes in Golestan Province who were attended to the only specialized diabetes clinic supported by Golestan University of Medical Sciences.

\section{Acknowledgements}

This article was written out of Maryam Farsinia's thesis for general medicine, registered as 535 in October 2012, School of Medicine, Golestan University of Medical Sciences. The author hereby wishes to thank Research Deputy of the School and University, and all who helped in this study, especially patients with type 2 diabetes for their cooperation and completion of questionnaire.

\section{Authors' Contributions}

Study concept and design: Dr Firooze Derakhshanpour and Dr Mohammad Ali Vakili; Acquisition of data: Kamal Mirkarimi; Analysis and interpretation of data: Dr Mohammad Ali Vakili and Kamal Mirkarimi; Drafting of the manuscript: Dr Firooze Derakhshanpour and Dr Mohammad Ali Vakili; Critical revision of the manuscript for important intellectual content: Dr Mohammad Ali Vakili; Statistical analysis: Dr Mohammad Ali Vakili. Administrative, technical, and material support: Dr Mohammad Ali Vakili and Dr Maryam Farsinia; Study supervision: Dr Firooze Derakhshanpour.

\section{Funding/Support}

This survey was financially supported by Golestan University of Medical Sciences. 


\section{References}

1. Ahmann AJ. Guidelines and performance measures for diabetes. Am J Manag Care. 2007;13 Suppl 2:S41-6.

2. Azizi F, Hatami H, Janghorbani M. Epidemiology and control of common diseases in Iran.Tehran: Eshtiagh Publications; 2000.

3. Rathmann W, Giani G. Global prevalence of diabetes: estimates for the year 2000 and projections for 2030. Diabetes Care. 2004;27(10):2568-9.

4. Larijani B, Abolhasani F, Mohajeri-Tehrani MR, Tabtabaie O. Prevalence of diabetes mellitus in Iran in 2000. Iran Diabetes Metab. 2005;4(3):75-83.

5. Ali S, Stone MA, Peters JL, Davies MJ, Khunti K. The prevalence of co-morbid depression in adults with Type 2 diabetes: a systematic review and meta-analysis. Diabet Med. 2006;23(11):1165-73.

6. Barnard KD, Skinner TC, Peveler R. The prevalence of co-morbid depression in adults with Type 1 diabetes: systematic literature review. Diabet Med. 2006;23(4):445-8.

7. Asghar S, Hussain A, Ali SM, Khan AK, Magnusson A. Prevalence of depression and diabetes: a population-based study from rural Bangladesh. Diabet Med. 2007;24(8):872-7.

8. Khamseh ME, Baradaran HR, Rajabali H. Depression and diabetes in Iranian patients: a comparative study. Int J Psychiatry Med. 2007;37(1):81-6.

9. Sepehrmanesh Z, Sarmast H, Sadr SF, Sarbolouki S. Prevalence and severity of depression in diabetic subjects. KAUMS J (FEYZ). 2003;7(3):69-75.

10. Connell CM, Fisher EB, Houston CA. Relationships among social support, diabetes outcomes, and morale for older men and women. J Aging Health. 1992;4(1):77-100.

11. de Groot M, Anderson R, Freedland KE, Clouse RE, Lustman PJ. Association of depression and diabetes complications: a metaanalysis. Psychosom Med. 2001;63(4):619-30.

12. DiMatteo MR, Lepper HS, Croghan TW. Depression is a risk factor for noncompliance with medical treatment: meta-analysis of the effects of anxiety and depression on patient adherence. Arch Intern Med. 2000;160(14):2101-7.

13. Kinder LS, Kamarck TW, Baum A, Orchard TJ. Depressive symptomatology and coronary heart disease in Type I diabetes mellitus: a study of possible mechanisms. Health Psychol. 2002;21(6):542-52.

14. Lustman PJ, Anderson RJ, Freedland KE, de Groot M, Carney RM Clouse RE. Depression and poor glycemic control: a meta-analytic review of the literature. Diabetes Care. 2000;23(7):934-42.

15. Egede LE, Zheng D, Simpson K. Comorbid depression is associated with increased health care use and expenditures in individuals with diabetes. Diabetes Care. 2002;25(3):464-70.

16. Rubin RR, Peyrot M. Quality of life and diabetes. Diabetes Metab Res Rev. 1999;15(3):205-18.

17. Alonso J, Angermeyer MC, Bernert S, Bruffaerts R, Brugha TS, Bryson $\mathrm{H}$, et al. Sampling and methods of the European Study of the Epidemiology of Mental Disorders (ESEMeD) project. Acta Psychiatr Scand Suppl. 2004(420):8-20.

18. de Grauw WJ, van de Lisdonk EH, Behr RR, van Gerwen WH, van den Hoogen HJ, van Weel C. The impact of type 2 diabetes mellitus on daily functioning. Fam Pract. 1999;16(2):133-9.

19. Baghiani Moghadam MH, Afkhami Ardakani M, Mazloumi SS, Saaidizadeh M. Quality of life in diabetes type II patients in Yazd.
J Shahid Sadoughi Univ Med Sci Health Serv. 2007;14:49-54.

20. Egede LE. Diabetes, major depression, and functional disability among U.S. adults. Diabetes Care. 2004;27(2):421-8.

21. Li C, Ford ES, Zhao G, Ahluwalia IB, Pearson WS, Mokdad AH Prevalence and correlates of undiagnosed depression among U.S. adults with diabetes: the Behavioral Risk Factor Surveillance System, 2006. Diabetes Res Clin Pract. 2009;83(2):268-79.

22. Kahn LS, Fox CH, McIntyre RS, Tumiel-Berhalter L, Berdine DE, Lyle $\mathrm{H}$. Assessing the prevalence of depression among individuals with diabetes in a Medicaid managed-care program. Int J Psychiatry Med. 2008;38(1):13-29.

23. Ciechanowski PS, Katon WJ, Russo JE. Depression and diabetes: impact of depressive symptoms on adherence, function, and costs. Arch Intern Med. 2000;160(21):3278-85.

24. Filakovic P. Terapija depresija kod bolesnika s komorbiditetom. MEDICUS. 2004;13(1_Depresija):59-67.

25. Eren I, Erdi O, Sahin M. The effect of depression on quality of life of patients with type II diabetes mellitus. Depress Anxiety. 2008;25(2):98-106.

26. Kaviani H, Mousavi A. Psychometric properties of the Persian version of Beck Anxiety Inventory (BAI). Tehran Univ Med J. 2008;66(2):136-40.

27. Diez-Quevedo C, Rangil T, Sanchez-Planell L, Kroenke K, Spitzer RL. Validation and utility of the patient health questionnaire in diagnosing mental disorders in 1003 general hospital Spanish inpatients. Psychosom Med. 2001;63(4):679-86.

28. Nedjat S, Montazeri A, Holakouie K, Mohammad K, Majdzadeh R. Psychometric properties of the Iranian interview-administered version of the World Health Organization's Quality of Life Questionnaire (WHOQOL-BREF): a population-based study. BMC Health Serv Res. 2008;8:61.

29. Nejat S, Montazeri A, Holakouie Naieni K, Mohammad K, Majdzadeh SR. The World Health Organization quality of Life (WHOQOL-BREF) questionnaire: Translation and validation study of the Iranian version. J Sch Public Health Inst Public Health Res. 2006;4(4):1-12.

30. Skevington SM, Lotfy M, O'Connell KA, Whoqol Group . The World Health Organization's WHOQOL-BREF quality of life assessment: psychometric properties and results of the international field trial. A report from the WHOQOL group. Qual Life Res. 2004;13(2):299-310.

31. Vakili Z, Mohamad AR, Vakili MA. A Quantitative Study of Quality of Life (QOL) on Postgraduate Students in Universiti Sains Malaysia. Caspian J Appl Sci Res. 2012;1(7).

32. Sadat Z, Abedzadeh-Kalahroudi M, Kafaei Atrian M, Karimian Z, Sooki Z. The Impact of Postpartum Depression on Quality of Life in Women After Child's Birth. Iran Red Crescent Med J. 2014;16(2):e14995.

33. Pinquart M, Duberstein PR. Depression and cancer mortality: a meta-analysis. Psychol Med. 2010;40(11):1797-810.

34. Lin EH, Katon W, Von Korff M, Rutter C, Simon GE, Oliver M, et al Relationship of depression and diabetes self-care, medication adherence, and preventive care. Diabetes Care. 2004;27(9):2154-60.

35. Unutzer J, Patrick DL, Diehr P, Simon G, Grembowski D, Katon W. Quality adjusted life years in older adults with depressive symptoms and chronic medical disorders. Int Psychogeriatr. 2000;12(1):15-33. 